\title{
Osteossarcoma apendicular em um felino
}

\author{
Appendicular osteosarcoma in a feline \\ Tuane Nerissa Alves Garcez' ${ }^{1}$ Cristiano Gomes², Kelly Cristini Rocha da Silva Ferreira ${ }^{2}$, \\ Rosemari Teresinha de Oliveira ${ }^{2,3}$, Anamaria de Oliveira Fernandes' ${ }^{2}$, \\ Carolina da Silva Cardoso² \& Luciana Oliveira de Oliveira ${ }^{2}$
}

\begin{abstract}
RESUMO
Tumores ósseos primários são raros em felinos, afetando gatos adultos ou idosos e com predileção pelo esqueleto apendicular. Nesta espécie, o índice de desenvolvimento de metástases é baixo e a amputação é um método eficaz de tratamento. A proposta deste trabalho é relatar um caso de osteossarcoma apendicular em um felino, sem raça definida, fêmea, de 16 anos de idade, apresentando aumento de volume na porção distal do úmero do membro anterior direito. Ao exame físico, o paciente apresentava claudicação e encontrava-se ativo e em bom estado nutricional. Foi solicitado hemograma completo, perfil bioquímico e avaliação radiológica do tórax e do membro afetado. Os valores de fosfatase alcalina (FA) e uréia encontravam-se aumentados. Os exames radiográficos indicaram imagem sugestiva de tumor ósseo, com presença de lise e perda da continuidade óssea do membro e as radiografias torácicas não apresentaram imagens compatíveis com metástases pulmonares. O paciente foi estabilizado e encaminhado para o centro cirúrgico para realização de escapulectomia e posterior terapia com carboplatina. $\mathrm{O}$ animal demonstrou boa recuperação pós-cirúrgica e leve toxicidade relacionada à quimioterapia com linfopenia e emese.
\end{abstract}

Descritores: oncologia, tumor ósseo, carboplatina, amputação.

\begin{abstract}
Primary bone tumors are rare in cats, affecting cats or elderly adults cats and with a predilection for the apendicular skeleton. In this species, the development of metastases is low and amputation is an efective treatment. The aim of this work is to report a case of apendicular osteosarcoma in a 16 year-old female cat, mixed breed with a nodule in the distal humerus. On physical examination the patient was limping, active and in good nutritional status. Complete blood count, biochemical profile and radiological assessment of the chest and limb were requested. The values of alkaline phosphatase (ALP) and urea were increased. The radiographic examinations showed suggestive bone tumor image, with lysis and loss of bone continuity of the right front member, and chest radiographs showed no compatible images of lung metastases. The patient was stabilized and transferred to the surgical center to perform escapulectomy and subsequent carboplatin therapy. The animal showed good post-surgical recovery, and low toxicity related to chemotherapy with lymphopenia and emesis.
\end{abstract}

Keywords: oncology, bone tumor, carboplatin, amputation.

${ }^{1}$ M V. Residente do Hospital de Clínicas Veterinárias (HCV) da Universidade Federal do Rio Grande do Sul (UFRGS), Av. Bento Gonçalves no 9090 , 91540-000 Porto Alegre, Bairro Agronomia, RS, Brasil. ${ }^{2}$ Serviço de Oncologia Veterinária, Hospital de Clínicas Veterinárias (HCV) - UFRGS. ${ }^{3}$ Setor de Patologia Veterinária, Departamento de Patologia Clínica Veterinária (DPCV), FaVet - UFRGS. CORRESPONDÊNCIA: T. N. A. Garcez [Email: tuane.garcez@gmail.com - Fax:+55 (51)3308 7305]. 


\section{INTRODUÇÃO}

Tumores ósseos primários são raros em felinos. Estima-se que a incidência destas neoplasias seja de 4,9:100.000 felinos. Dentre esses, o osteossarcoma é o mais comum, afetando gatos adultos ou idosos e com predileção pelo esqueleto apendicular $[6,7]$.

O exame radiográfico do local afetado revela alterações semelhantes ao osteossarcoma canino, com lesões osteolíticas. O diagnóstico definitivo é obtido pela histopatologia [4].

A espécie felina apresenta baixo índice de metástases provenientes de tumores ósseos, especialmente do osteossarcoma. Assim, a amputação representa um método eficiente de tratamento em gatos [7]. Quando há formação de metástases, estas geralmente desenvolvem-se nos pulmões, linfonodos regionais e rins. Nos casos em que a margem cirúrgica esteja comprometida, ou haja presença de metástase, recomendase quimioterapia adjuvante [1].

Há poucos relatos na literatura de osteossarcoma apendicular em felinos. O objetivo deste trabalho é relatar um caso clínico de osteossarcoma apendicular em um felino e revisar os aspectos mais importantes desta neoplasia, bem como as possibilidades de tratamento.

\section{RELATO DE CASO}

Um felino, fêmea, sem raça definida (SRD), de 16 anos de idade, foi encaminhado ao Setor de Oncologia Veterinária do Hospital de Clínicas Veterinárias $(\mathrm{HCV})$ da Universidade Federal do Rio Grande do Sul (UFRGS), devido à presença de uma massa na face lateral do membro torácico direito, na região distal do úmero. $\mathrm{O}$ animal não possuía histórico de trauma nem de vacinação no local da lesão. Ao exame físico, o paciente apresentava claudicação e encontrava-se ativo e em bom estado nutricional. À palpação, observou-se aumento bilateral de volume dos linfonodos submandibulares e subescapulares. A massa tumoral apresentava-se aderida, firme e o animal mostrava sinais de dor local.

Foram realizados hemograma completo, perfil bioquímico e avaliação radiológica do tórax e do membro afetado. Não foi possível a realizaçãoda $\mathrm{BAAF}^{1}$, devido à consistência firme do nódulo. Os resultados do hemograma encontravam-se dentro dos parâmetros normais e os valores da enzima fosfatase alcalina (FA) e uréia estavam aumentados. $\mathrm{O}$ exame radiográfico do membro acometido revelou imagem sugestiva de tumor ósseo, com presença de lise e perda da continuidade óssea. As radiografias torácicas não indicaram imagens compatíveis com metástases pulmonares.

O paciente foi encaminhado ao centro cirúrgico para escapulectomia (Figura $1 \mathrm{~A}$ e B) e o material, enviado para a análise histopatológica. $\mathrm{O}$ felino retornou para revisão e retirada dos pontos 10 dias após o procedimento cirúrgico, encontrando-se bem disposto e apresentando boa cicatrização da ferida cirúrgica. $\mathrm{O}$ laudo histopatológico confirmou o diagnóstico de osteossarcoma. A Figura 2 mostra a aparência do felino no pós-operatório, já evidenciando o crescimento dos pelos.

Optou-se pelo tratamento quimioterápico com carboplatina $^{2}$, por via endovenosa, na dosagem de $200 \mathrm{mg} / \mathrm{m}^{2}$, em intervalo de três semanas. O paciente apresentou episódios de vômito e diarréia após as aplicações e o hemograma repetido no nadir da primeira administração revelou linfopenia, sendo prescrito timomodulina $^{3}$. Em virtude dos sinais gastrintestinais apresentados pelo felino, a proprietária optou pela suspensão da quimioterapia após a terceira sessão. $\mathrm{Na}$ revisão, aos seis meses, foram realizados ultrassonografia (US) abdominal e RX de tórax. A US abdominal revelou linfonodos paralombares aumentados e o RX torácico apresentou imagem compatível com metástase pulmonar.

\section{DISCUSSÃO}

Os sinais clínicos de tumores ósseos em felinos, como claudicação e aumento de volume, e as lesões radiográficas de lise e perda da continuidade óssea [4], foram observados neste caso. A confirmação da neoplasia foi obtida através da histopatologia, conforme recomendado na literatura [10].

Em felinos, os membros mais acometidos são os posteriores [4], porém, o presente relato, apresenta um caso de osteossarcoma no membro anterior. $\mathrm{O}$ paciente demonstrou uma boa recuperação dos movimentos nos primeiros dias após a cirurgia, retornando às funções que realizava anteriormente, como caminhar, correr e saltar. Para lesões nos membros torácicos, a amputação completa do membro, incluindo a escápula, apresenta bons resultados estéticos e funcionais. A amputação controla o tumor primário e fornece alívio da dor, com pouca ou nenhuma redução na mobilidade e qualidade de vida, o que faz com que o procedimento seja, em geral, bem aceito pelos proprietários [9]. 


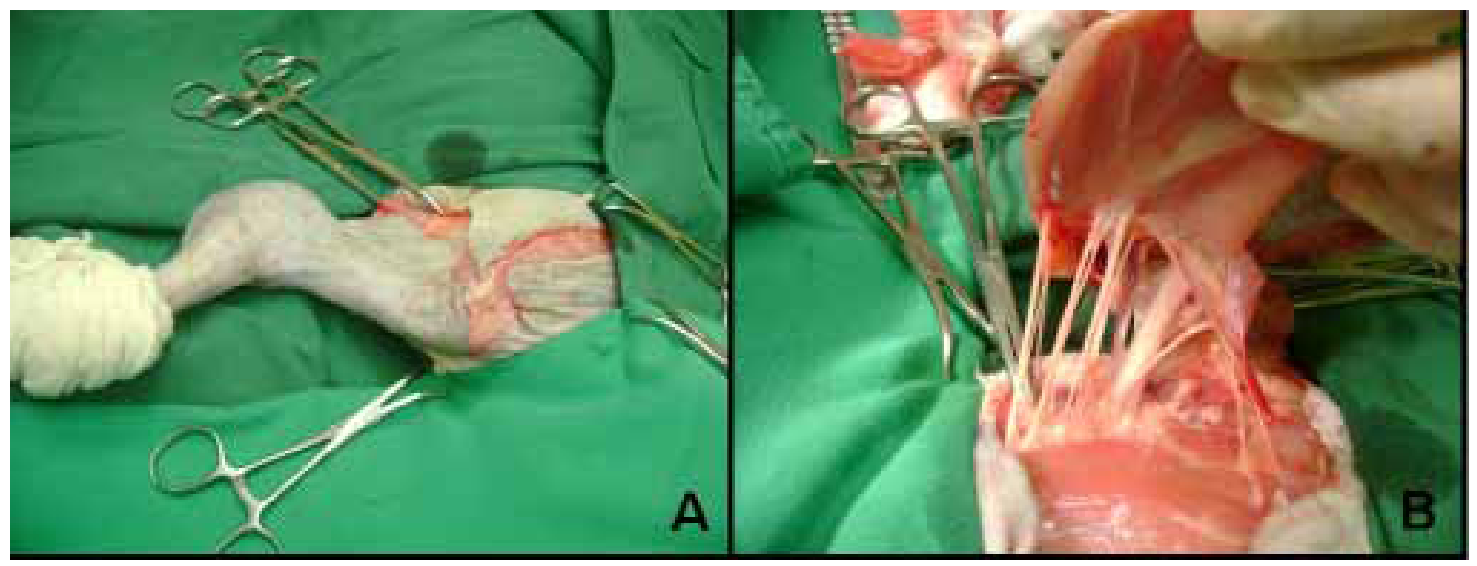

Figura 1. [A] Felino, fêmea, SRD, de 16 anos de idade, durante o procedimento cirúrgico para escapulectomia, nota-se o aumento de volume na porção distal do úmero (seta). [B] Localização dos vasos e nervos do plexo braquial.

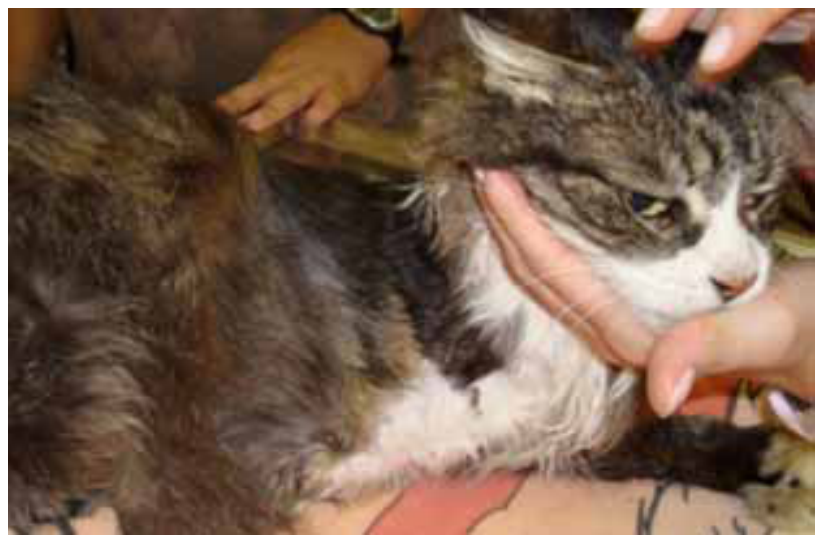

Figura 2. Aparência do felino, fêmea, SRD de 16 anos de idade submetido à amputação do membro anterior direito após o crescimento dos pelos.

A FA aumentada sugere uma lesão hepática ou, ainda, pode ser correlacionada a um pior prognóstico quanto à sobrevida do animal [5]. Estudos têm mostrado que essa enzima reflete a extensão da neoplasia no momento do diagnóstico, pois está relacionada à atividade celular e, quanto maior a disseminação das células neoplásicas, maior o nível sérico da mesma [2]. Considerando o aumento dos níveis de FA e o aumento bilateral de linfonodos submandibulares e subescapulares como fatores prognóstico negativos, visto que demais valores indicativos de função hepática estavam normais, optou-se por instituir o protocolo quimioterápico. Este procedimento mostrou-se seguro, apresentando leves sinais de toxicidade gastrintestinal, como episódios de vômito, e mielotoxicidade. Os problemas digestivos estão relacionados entre os mais comumente observados e a sua repercussão clínica é menos grave do que a toxicidade hematológica [8]. Entretanto, o surgimento de sinais digestivos levou o proprietário a optar pela suspensão do tratamento. Sem terapia adjuvante, a sobrevida média de gatos com osteossarcoma varia de 24 a 44 meses [10]. O animal deste relato já demonstrava, ao início do tratamento, sinais de pior prognóstico, devido à presença de linfonodos reativos e ao aumento do nível de FA. Apesar de acreditar-se que o tratamento cirúrgico combinado à quimioterapia adjuvante pudesse resultar em um melhor prognóstico, o animal demonstrou imagem radiográfica compatível com metástases pulmonares após oito meses do diagnóstico e tratamento quimioterápico com carboplatina.

\section{NOTAS INFORMATIVAS}

${ }^{1}$ Biópsia aspirativa por agulha fina.

${ }^{2}$ Paraplatin - Bristol Myers Squibb Farmacêutica Ltda., São Paulo, SP, Brasil.

${ }^{3}$ Leucogen - Aché Laboratórios Farmacêuticos S/A, São Paulo, SP, Brasil.

\section{REFERÊNCIAS}

1 Bennett D. 2004. Feline bone diseases. In: Anais do 12th ESVOT Congress (Munich, Alemanha). p.15.

2 Castro H.C., Ribeiro K.B. \& Bruniera P. 2008. Osteossarcoma: experiência do Serviço de Oncologia Pediátrica da Santa Casa de Misericórdia de São Paulo. Revista Brasileira de Ortopedia. 43: 108-115.

3 Couto C.G. 1992. Neoplasias Selecionadas em Cães e Gatos. In: Nelson R.W. \& Couto C.G. (Eds). Medicina interna de pequenos animais. Rio de Janeiro: Guanabara Koogan, pp.899-901.

4 Dernell W.S. 2003. Tumours of the Skeletal System. In: Dobson J.M. \& Lascelles B.X. (Eds). Bsava manual of canine and feline oncology. 2nd edn. Gloucester: BSAVA, pp.179-195. 
5 Erhart N., Dernell W.S., Hoffmann W.E., Weigel R.M., Powers B.E. \& Withrow S.J. 1998. Prognostic importance of alkaline phosphatase activity in serum from dogs with appendicular osteosarcoma: 75 cases (1990-1996). Journal of American Veterinary Medical Association. 213: 1002-1006.

6 Heldmann E., Anderson M.A. \& Wagner-Mann G. 2000. Feline osteosarcoma: 145 cases (1990-1995). Journal of the American Animal Hospital Association. 36: 518-521.

7 Kleiner J.A. \& Silva E.G. 2003. Tumores ósseos em pequenos animais. Revista Medvep. 1: 21-33.

8 Lanore D. \& Delprat C. 2004. Quimioterapia Anticancerígena. São Paulo: ROCA, 191p.

9 Ogilvie G.K. 2004. Tumores Ósseos. In: Rosenthal R.C. (Ed). Segredos em oncologia veterinária. Porto Alegre: Artmed, pp.183-191.

10 Vail D.M. \& Withrow S.J. 2001. Tumors of the Skeletal System. In: Withrow S.J. \& Macewen E.G. (Eds). Small animal clinical oncology. 4th edn. Philadelphia: W. B. Saunders, pp. 540-582. 